\title{
Estudo da influência das condições de síntese do método dos precursores poliméricos na formação de perovsquitas do tipo $\mathrm{LaNiO}_{3}$
}

\section{(Study of the influence of the synthesis conditions of the precursor polymeric method for $\mathrm{LaNiO}_{3}$ perovskite type formation)}

\author{
M. C. Alves ${ }^{1}$, S. O. Souza ${ }^{1}$, J. C. Santos ${ }^{1}$, M. J. B. Souza ${ }^{2}$, A. M. G. Pedrosa ${ }^{1}$ \\ ${ }^{1}$ Departamento de Química, ${ }^{2}$ Departamento de Engenharia Química, Universidade Federal de Sergipe, Cidade \\ Universitária Professor José Aloísio de Campos, Av. Marechal Rondon, s/n, Jardim Rosa Elze, São Cristóvão,
}

SE 49100-000

annemgp@ufs.br

\begin{abstract}
Resumo
A perovsquita do tipo $\mathrm{LaNiO}_{3}$ é um material que exibe aplicações em diversas áreas como catálise, óptica, células a combustível de óxido sólido, etc.. Neste trabalho, a otimização da síntese de perovsquitas do tipo $\mathrm{LaNiO}_{3}$ foi feita pelo método dos precursores poliméricos, modificando as razões metal/ácido cítrico e etilenoglicol/ácido cítrico. Em geral, as propriedades destes materiais variam com a composição e com o método de síntese. Os materiais sintetizados foram caracterizados por difração de raios $\mathrm{X}$, análise termogravimétrica e espectroscopia de infravermelho. As perovsquitas com razões metal/ácido cítrico $(1,0 / 1,0)$ e etilenoglicol/ácido cítrico (60/40) apresentaram melhores resultados em relação à obtenção da fase perovsquita monofásica.
\end{abstract}

Palavras-chave: $\mathrm{LaNiO}_{3}$, influência da condição de síntese, método dos precursores poliméricos.

\section{Abstract}

The $\mathrm{LaNiO}_{3}$ perovskite is a material that displays applications in several areas as catalysis, optics, in solid oxide fuel cells, etc. In this work the optimization of the synthesis of $\mathrm{LaNiO}_{3}$ perovskite was performed using the polymeric precursor method, modifying the metal/citric acid and ethyleneglycol/citric acid ratios. In general, the properties of these materials vary with the composition and the synthesis method. The materials were characterized by X-ray diffraction, thermal gravimetric analysis and Fourier transform infrared spectroscopy. The perovskite with ratios metal/citric acid (1.0/1.0) and ethylene glycol/citric acid (60/40) showed better results to obtain the perovskite monophasic phase.

Keywords: $\mathrm{LaNiO}_{3}$, synthesis condition influence, polymeric precursor method.

\section{INTRODUÇÃO}

Nos últimos anos, várias pesquisas têm sido focadas no desenvolvimento de novas rotas para a síntese de óxidos do tipo perovsquitas, a fim de controlar a morfologia do produto final e a pureza da fase desejada. Estes esforços são conseqüências das perovsquitas serem consideradas materiais estratégicos de interesse mundial, devido as suas interessantes propriedades, tais como ferroelétricas, magnéticas, eletrônicas, ópticas e catalíticas, dentre outras. Perovsquitas são óxidos mistos com fórmula geral $\mathrm{ABO}_{3}$, em que o cátion no sítio A é uma terra rara e/ ou alcalino terroso e o cátion no sítio $\mathrm{B}$ é um metal de transição $3 \mathrm{~d}$, no estado oxidação +3 [1-4].

$\mathrm{LaNiO}_{3}$ pertence ao grupo de materiais com estrutura perovsquita, mostra caráter metálico, que é bastante incomum em óxidos, e é bem conhecido como um óxido bom condutor de eletricidade aplicado como material de elétrodo em dispositivos eletrônicos [3, 5]. Este material é bem conhecido por ser uma perovsquita romboédrica, que apresenta um caráter metálico abaixo de 4,2 K. As propriedades elétricas e magnéticas destes óxidos são regidas pelos efeitos de correlação eletrônica forte [5]. Uma característica interessante desses óxidos mistos é que a sua atividade catalítica pode ser altamente melhorada pela substituição parcial nos sítios A e/ou B, com apenas pequenas mudanças na estrutura média $[4,6]$. Tanto os cátions no sítio A quanto no B podem ser substituído por diferentes cátions, A' e B', melhorando a estabilidade estrutural da perovsquita e introduzindo defeitos estruturais (vacâncias de oxigênio) e eletrônicos. A substituição parcial do cátion no sítio A por um íon de valência diferente mostrou influenciar a atividade catalítica por estabilizar o cátion no sítio B em estados de oxidações incomuns [6]. 
Para a síntese dos óxidos tipo perovsquita, o método dos precursores poliméricos tem mostrado sucesso na síntese de pós monofásicos em temperaturas relativamente baixas [7]. O método se baseia na formação de quelatos entre cátions dissolvidos e um ácido $\alpha$-hidroxicarboxílico, tal como ácido cítrico, e a poliesterificação na presença de um poli(álcool hidroxílico) [7-9]. Dentre vários sais disponíveis, os nitratos são preferidos pela eliminação relativamente fácil durante a calcinação [8]. Diversos trabalhos estudaram a síntese de óxidos com estrutura perovsquita pelo método dos precursores poliméricos onde foi usado várias razões entre metal (M) e o ácido cítrico (AC) e entre o $\mathrm{AC}$ e o etilenoglicol (EG) na síntese de óxidos mistos. Estes diversos autores estudaram o efeito dessas razões na pureza, tamanho de partícula e propriedades de diversos produtos de óxidos mistos [9-13]. No presente trabalho, perovsquitas do tipo $\mathrm{LaNiO}_{3}$ foram sintetizadas pelo método dos precursores poliméricos, com objetivo de otimizar as condições de síntese, através da investigação do efeito das razões entre teor de metal (níquel) e o ácido cítrico e entre o teor deste em relação a quantidade de etilenoglicol na formação da fase perovsquita.

\section{MATERIAIS E MÉTODOS}

O niquelato de lantânio foi obtido pelo método dos precursores poliméricos, derivado do método Pechini [14]. Em um meio aquoso, sob agitação constante, a uma temperatura de aproximadamente $60{ }^{\circ} \mathrm{C}$ foram adicionadas quantidades de ácido cítrico (AC) e dos sais metálicos, nas proporções de $\mathrm{M} / \mathrm{AC}$ de $(1 / 1,1 / 1,5$ e 1/2). Em seguida, foi adicionado o etilenoglicol, nas proporções de $\mathrm{AC} / \mathrm{EG}$ em massa percentual de (40/20, 50/30 e 60/40). Após a adição de todos os reagentes, a solução foi aquecida a uma temperatura de aproximadamente $90{ }^{\circ} \mathrm{C}$, com o objetivo de promover a esterificação, formando um gel polimérico, de coloração verde e límpido, chamado resina. Cada resina foi levada ao forno mufla para uma calcinação primária a $300{ }^{\circ} \mathrm{C}$ por 2 h, para a obtenção de uma resina expandida (puff). Em seguida, o puff foi desaglomerado com auxilio de almofariz, caracterizado por análise termogravimétrica e espectroscopia de infravermelho e em seguida foi submetido a uma segunda calcinação a $700{ }^{\circ} \mathrm{C}$ por $1 \mathrm{~h}$. Após a calcinação, as amostras foram caracterizadas por difração de raios X.

A decomposição térmica do material tratado termicamente a $300{ }^{\circ} \mathrm{C}$ por $2 \mathrm{~h}$ foi estudada a partir da análise termogravimétrica em equipamento TA Instruments, em atmosfera de nitrogênio, com fluxo de $100 \mathrm{~mL} / \mathrm{min}$. Foi utilizado um cadinho de platina, contendo de 4 a $10 \mathrm{mg}$ de amostra, que foram analisadas de 30 a $900{ }^{\circ} \mathrm{C}$, com taxa de aquecimento $10^{\circ} \mathrm{C} / \mathrm{min}$. Os espectros de absorção na região do infravermelho dos materiais sintetizados e submetidos ao tratamento térmico de $300{ }^{\circ} \mathrm{C}$ por $2 \mathrm{~h}$ foram obtidos em um espectrofotômetro Perkin-Elmer Spectrum BX na região de 4000 a $400 \mathrm{~cm}^{-1}$. As amostras foram dispersas em $\mathrm{KBr}$ e prensadas na forma de pastilhas.

Os difratogramas de raios $\mathrm{X}$ das perovsquitas do tipo
$\mathrm{LaNiO}_{3}$ calcinadas a $700{ }^{\circ} \mathrm{C}$ por $1 \mathrm{~h}$ foram obtidos numa varredura angular de 10 a $70^{\circ}$, com radiação Cuk $\alpha$ e filtro de $\mathrm{Ni}$, com uma voltagem e corrente do tubo de $40 \mathrm{kV}$ e 40 $\mathrm{mA}$, respectivamente. A abertura da fenda foi $10 \mathrm{~mm}$ e a varredura foi $0,2^{\circ} / \mathrm{min}$ e passo $0,02^{\circ}$. Os resultados foram analisados e comparados com as fichas cristalográficas do JCPDS.

\section{RESULTADOS E DISCUSSÃO}

Os espectros de absorção na região do infravermelho das amostras sintetizadas e tratadas termicamente a $300{ }^{\circ} \mathrm{C}$ podem ser vistos na Fig. 1. Todos os espectros mostram bandas largas entre 3700 e $3400 \mathrm{~cm}^{-1}$, às quais indicam a presença do estiramento $v(\mathrm{O}-\mathrm{H})$ do citrato [1]. A banda fraca próximo a $1074 \mathrm{~cm}^{-1}$ deve-se ao estiramento $\mathrm{v}(\mathrm{C}-\mathrm{O})$ associado à formação do ester pelo grupo $-\mathrm{CH}_{2}-\mathrm{OH}$ do etilenoglicol com o grupo $\mathrm{COO}^{-}$do ácido cítrico. As bandas fortes entre 1580 a $1300 \mathrm{~cm}^{-1}$ são relacionadas aos estiramentos assimétrico $v_{a s}(\mathrm{COO})$ e simétrico $v_{s}(\mathrm{COO})$ do grupo carboxila, respectivamente, que confirmam a coordenação dos íons metálicos por grupos carboxilatos na forma de um complexo bidentado. Nos espectros também é possível observar um deslocamento da banda que indica óxidos estiramento $v(\mathrm{M}-\mathrm{O})$ em $590 \mathrm{~cm}^{-1}$ para aproximadamente $680 \mathrm{~cm}^{-1}$ [15]. Os espectros de infravermelho de todas as amostras são muito similares, o que sugere que em todos os casos há a coordenação do ligante ao metal e é sugestivo de ligação do tipo quelato.

As curvas termogravimétricas dos pós precursores das perovsquitas do tipo $\mathrm{LaNiO}_{3}$ preparados pelo método dos precursores poliméricos e variando a razão metal/ácido cítrico e ácido cítrico/etilenoglicol estão mostradas na Fig. 2 . A análise térmica fornece informações sobre as temperaturas de decomposição dos materiais obtidos durante a síntese e a temperatura de obtenção da fase óxido termicamente estável [16]. De acordo com os resultados, a reação de decomposição ocorre em três faixas de temperatura. A primeira perda de massa que ocorre entre 30 e $200{ }^{\circ} \mathrm{C}$ é devida à água adsorvida e início da decomposição de matéria orgânica do material precursor; a segunda, de 200 a $400{ }^{\circ} \mathrm{C}$, pode ser atribuída à decomposição da matéria orgânica dos precursores; e a terceira, entre 400 e $650{ }^{\circ} \mathrm{C}$, é freqüentemente relacionada à decomposição de carbonatos. Nas curvas TG é possível observar uma faixa onde ocorre um ganho de massa devido à oxidação do $\mathrm{Ni}^{2+}$ a $\mathrm{Ni}^{3+}$ pela presença de $\mathrm{NiO}$, que foi comprovado por difração de raios $X$. As curvas termogravimétricas indicaram que quanto menor o teor de agente polimerizante (etilenoglicol), maior foi a temperatura final de decomposição dos precursores da perovsquita (material tratado termicamente). A mesma tendência foi observada ao variar a proporção de ácido cítrico no meio: ao aumentar o teor de agente complexante (ácido cítrico), menor foi a temperatura final de decomposição dos materiais tratados termicamente. A condição melhor para formação da fase perovsquita foi a proporção ácido cítrico/etileno glicol 60/40. A proporção entre o metal (M) 

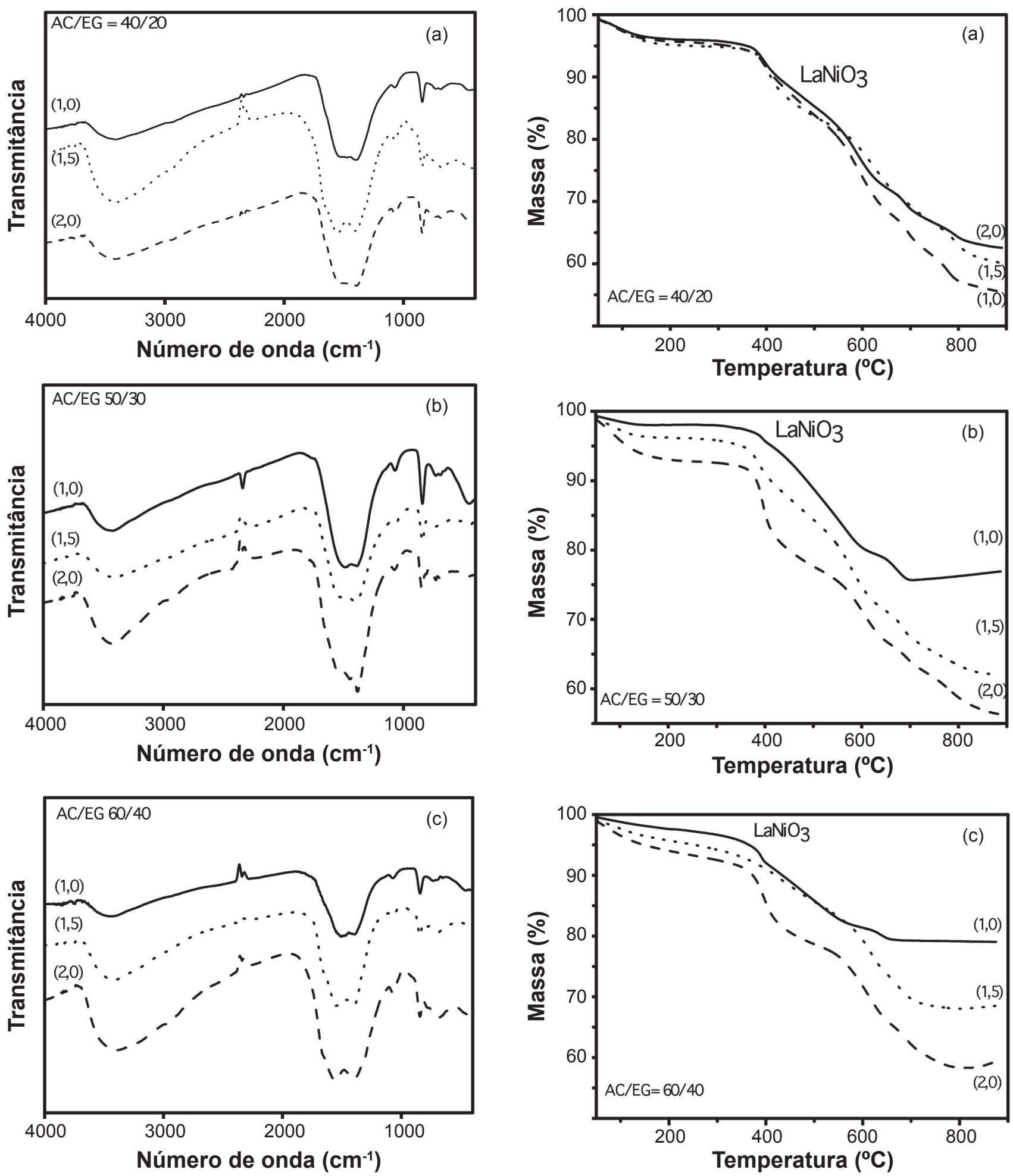

Figura 1: Espectros FTIR das perovsquitas com razão metal/AC (1/1, 1/1,5 e 1/2): (a) AC/EG = 40/20, (b) 50/30, (c) 60/40.

[Figure 1: FTIR spectra of perovskite with metal/citric acid ratios $(1 / 1,1 / 1.5$ and 1/2): (a) citric acid/ethylenglycol $=40 / 20$, (b) 50/30, (c) 60/40.]

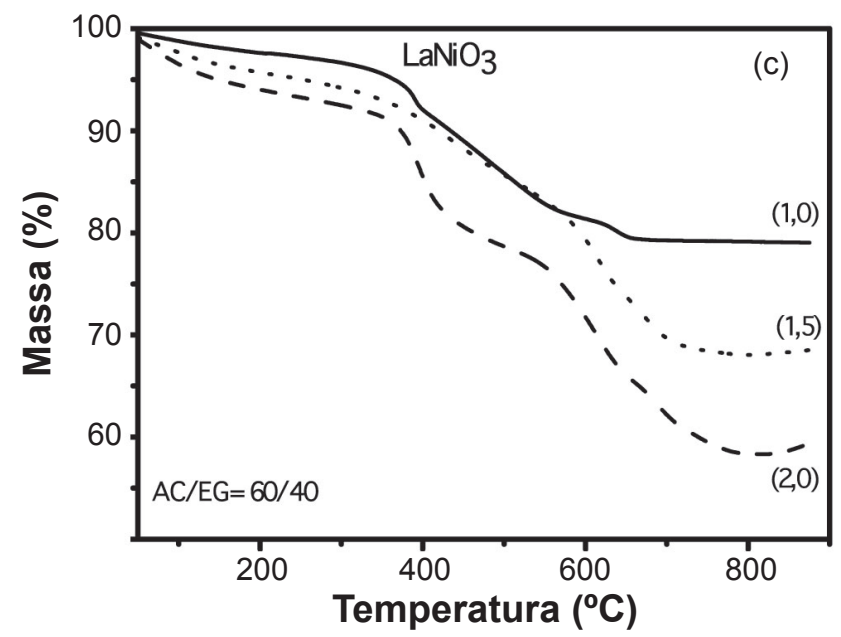

Figura 2: Curvas termogravimétricas das perovsquitas com razão metal/AC (1/1; 1/1,5 e 1/2): (a) AC/EG = 40/20, (b) 50/30, (c) 60/40. [Figure 2: Termogravimetric curves of the perovskites with metal/ $A C$ rations of $(1 / 1 ; 1 / 1.5$ and $1 / 2)$ : (a) citric acid/ethyleneglycol $=$ 40/20, (b) 50/30, (c) 60/40.]

e o ácido cítrico (AC) também influencia na estabilidade térmica do material tratado termicamente. A decomposição cessa a menores temperaturas para amostras com menores

razões $\mathrm{M} / \mathrm{AC}$, ou seja, a menor proporção de $\mathrm{M} / \mathrm{AC}$ leva à formação de um material termicamente estável a menores temperaturas. 

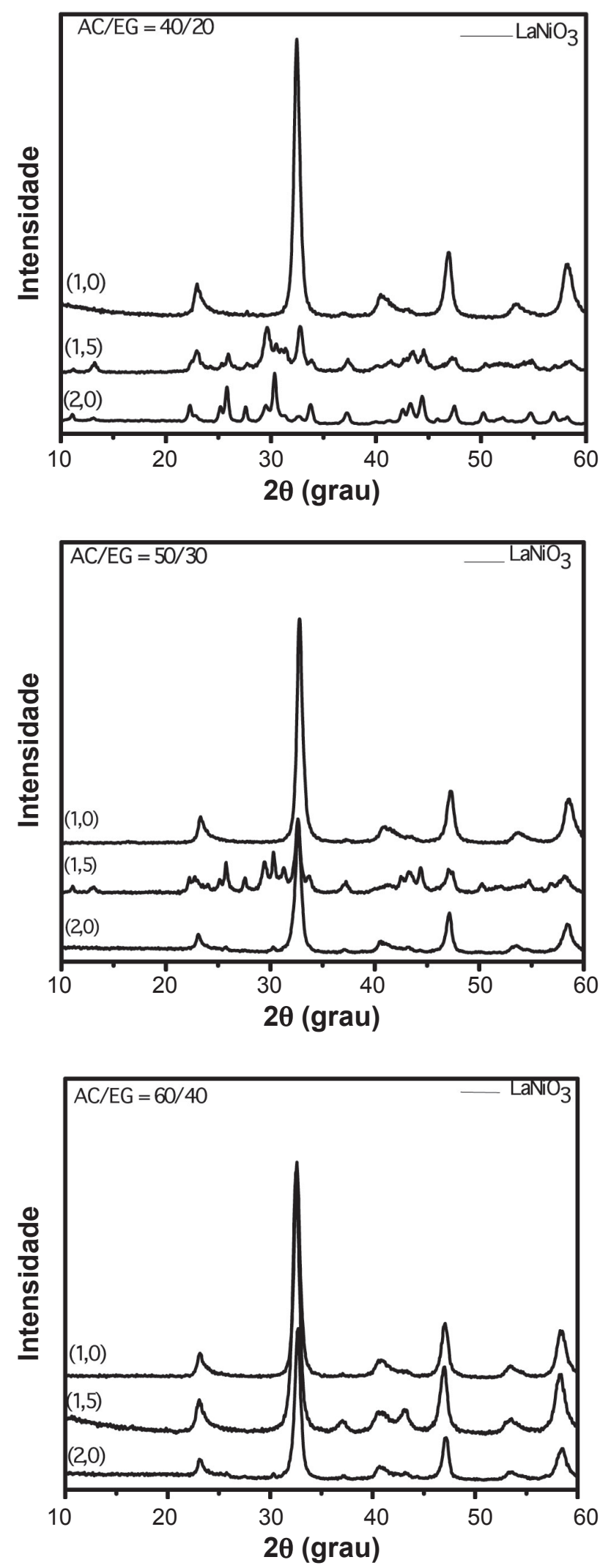

Figura 3: Difratogramas de raios $\mathrm{X}$ para as perovsquitas calcinadas a $700{ }^{\circ} \mathrm{C}$ e com razão metal/AC $(1 / 1 ; 1 / 1,5$ e $1 / 2)$ : (a) $\mathrm{AC} / \mathrm{EG}=$ 40/20, (b) 50/30, (c) 60/40.

[Figure 3: X-ray diffraction patterns of the perovskites calcined at $700{ }^{\circ} \mathrm{C}$ and with metal/citric acid ratios $(1 / 1 ; 1 / 1.5$ and $1 / 2):(a)$ citric acid/ethylene glycol $=40 / 20$, (b) 50/30, (c) 60/40.]
Os padrões de difração de raios $\mathrm{X}$ dos pós precursores do $\mathrm{LaNiO}_{3}$ preparados pelo método dos precursores poliméricos e variando a razão $\mathrm{AC} / \mathrm{EG}$ e $\mathrm{M} / \mathrm{AC}$ não mostraram fases cristalinas. A formação da fase perovsquita cristalina pode ser observada nos difratogramas dos pós calcinados a 700 ${ }^{\circ} \mathrm{C}$ por $1 \mathrm{~h}$ (Fig. 3). Para as amostras $\mathrm{LaNiO}_{3}$ calcinadas a $700{ }^{\circ} \mathrm{C}$ e razão $\mathrm{AC} / \mathrm{EG}(40 / 20)$ (Fig. 3a), somente a razão $\mathrm{M} / \mathrm{AC}(1 / 1)$ formou um material monofásico exibindo a estrutura perovsquita; as outras razões M/AC (1/1,5 e 1/2) formaram fases secundárias além da perovsquita. Nestas amostras a estrutura perovsquita foi caracterizada pelos picos mais intensos em $2 \theta=32,46^{\circ}, 46,94^{\circ}$ e $58,26^{\circ}$. Os difratogramas das amostras de $\mathrm{LaNiO}_{3}$ calcinadas a $700{ }^{\circ} \mathrm{C}$ por $1 \mathrm{~h}$ e preparadas com a razão AC/EG (50/30) (Fig. 3b), mostraram a formação de picos referentes à fase perovsquita bem definidos, exceto para a razão metal/ácido cítrico $1,0 / 1,5$. No entanto, a amostra preparada com a razão M/AC 1/1 foi a única que formou unicamente a fase perovsquita, ou seja, a perovsquita como única fase. Para esta amostra o difratograma de raios $X$ mostrou os picos em $2 \theta=$ $32,78^{\circ}, 47,24^{\circ}$, e $58,52^{\circ}$, que foram atribuídos à estrutura perovsquita [14]. No entanto, os pós preparados nas razões $\mathrm{M} / \mathrm{AC}$ de 1/1,5 e 1/2 apresentaram fases secundárias.

Os padrões de difração de raios $\mathrm{X}$ bem definidos foram obtidos para os pós precursores da perovsquita $\mathrm{LaNiO}_{3}$ (Fig. 3c) calcinados a $700{ }^{\circ} \mathrm{C}$ por $1 \mathrm{~h}$ e preparadas com a razão AC/EG (60/40). Todas as amostras apresentaram a formação de um pó monofásico com estrutura perovsquita, exceto para a razão metal/AC de 1/1,5 e 1/2 que formaram fases secundárias, $\mathrm{NiO}$, em menor quantidade para a amostra de razão de 1/2, além da fase perovsquita. Como amostra preparada com razão M/AC de 1/1 formou apenas a fase perovsquita, pode-se sugerir esta como a melhor razão para obtenção do pó monofásico na razão AC/EG de 60/40. Para esta amostra, o difratograma mostra os picos em $2 \theta=$ $32,6^{\circ}, 47,08^{\circ}$ e $58,3^{\circ}$. Com isso, sugere-se que as amostra preparadas com razão $\mathrm{AC} / \mathrm{EG}$ de $60 / 40$ seja a melhor na formação de pós com estrutura perovsquita.

Para todas as amostras variando a razão $\mathrm{AC} / \mathrm{EG}$, a melhor proporção $\mathrm{M} / \mathrm{AC}$ na formação de um pó monofásico com estrutura perovsquita foi a razão M/AC 1/1. No entanto, alguns estudos comparativos realizados para diferentes precursores obtiveram a melhor razão molar entre ácido cítrico e metal $(1 / 1,5)$ para a síntese dos pós perovsquita do tipo $\mathrm{La}_{0,6} \mathrm{Sr}_{0,4} \mathrm{Co}_{0,2} \mathrm{Fe}_{0,8} \mathrm{O}_{3-\delta}[17]$.

\section{CONCLUSÕES}

Materiais com estrutura perovsquita do tipo $\mathrm{LaNiO}_{3}$ foram sintetizados pelo método dos precursores poliméricos, modificando as razões entre o metal e o ácido cítrico e entre o etilenoglicol e o ácido cítrico. As curvas termogravimétricas indicaram que a temperatura de decomposição do material tratado termicamente é influenciada pelas condições de síntese, como da proporção de agentes polimerizantes ou complexantes do meio. Os espectros de absorção na região do infravermelho são sugestivos de que em todos os materiais 
em que há variação da proporção entre metal/ácido cítrico e entre ácido cítrico/etileno glicol é evidente a coordenação do metal ao poliéster formando um quelato. Os difratogramas de raios $\mathrm{X}$ indicaram que em todos os materiais estudados ocorre a formação da fase perovsquita, porém em algumas amostras esta não foi a única fase formada. Todas as análises realizadas para o material neste trabalho sugerem que a melhor condição para formação da fase perovsquita foi a proporção de ácido cítrico/etilenoglicol de 60/40 e na proporção $1 / 1$ entre o metal e o ácido cítrico em relação à obtenção da fase perovsquita monofásica e a menores temperaturas.

\section{AGRADECIMENTOS}

Ao CNPq, a CAPES e ao PIBIC/UFS, pelo apoio concedido.

\section{REFERÊNCIAS}

[1] J. D. G. Fernandes, D. M. A. Melo, L. B. Zinner, C. M. Salustiano, Z. R. Silva, A. E. Martinelli, M. Cerqueira, C. Alves Jr., E. Longo, M. I. B. Bernadi, J. Mater. Lett. 53 (2002) 122.

[2] C. Matei, D. Berger, P. Marote, S. Stoleriu, J. P. Deloume, Progr. Solid State Chem. 35 (2007) 203.

[3] N. T. H. Le, J. M. Calderón-Moreno, M. Popa, D. Crespo, L. V. Hong, N. X. Phuc, J. Eur. Ceram. Soc. 26 (2006) 403.
[4] M. R. Goldwasser, M. E. Rivas, E. Pietri, M. J. PérezZurit, M. L. Cubeiro, A. Grivobal-Constant, G. Leclercq, J. Molecular Catalysis A: Chem. 228 (2005) 325.

[5] W. Yao, H. Yang, Y. Chang, Y. Zhu, Appl. Surface Sci. 252 (2006) 7461.

[6] J. R. Mawdsley, T. R. Krause, Appl. Catalysis A: General 334 (2008) 311.

[7] D. S. Melo, E. P. Marinho, L. E. B. Soledade, D. M. A. Melo, S. J. G. Lima, E. Longo, I. M. G. Santos, A. G. Souza, J. Mater. Sci. 43 (2008) 551.

[8] R. H. R. Castro, D. Gouvêa, Cerâmica 51 (2005) 407.

[9] A. Gaki, O. Anagnostaki, D. Kioupis, T. Perraki, D. Gakis, G. Kakali, J. Alloys Compnd. 451 (2008) 305.

[10] M. T. Hernández, M. González, J. Eur. Ceram. Soc. 22 (2002) 2861.

[11] R. J. Bell, G. J. Millar, J. Drennan, Solid State Ionics 131 (2000) 211.

[12] W. D. Yang, Y. H. Chang, S. H. Huang, J. Eur. Ceram. Soc. 25 (2005) 3611.

[13] Y. Xu, X. Yuan, P. Lu, G. Huang, C. Zeng, Mater. Chem. Phys. 96 (2006) 427.

[14] M. Pechini, U.S. Patent 3,330,697 (1967).

[15] M. Gharagozlou, J. Alloys Compnd. 486 (2009) 660.

[16] A. M. Garrido Pedrosa, D. M. A. Melo, M. J. B. Souza, A. O. S. Silva, A. S. Araujo, J. Therm. Anal. Cal. 84 (2006) 503.

[17] J. Shao, Y. Tao, J. Wang, C. Xu, W. G. Wang, J. Alloys Compnd. 484 (2009) 263.

(Rec. 08/07/2010, Ac. 30/12/2010) 